ELKOM, Vol.11, No.2, Desember 2018, pp. 56 - 66

p-ISSN : 1907-0012 (print)

e-ISSN : 2714-5417 (online)

http://ejurnal.stekom.ac.id/index.php/home

- page 56

\title{
PENDAFTARAN SISWA BARU ONLINE DI SMK NEGERI 4 KENDAL
}

\author{
Haris Ihsanil Huda ${ }^{1}$; Maya Utami Dewi ${ }^{2}$ \\ ${ }^{1}$ Progdi Sistem Komputer - Sekolah Tinggi Elektronika dan Komputer (STEKOM), \\ haris.ihsanil.huda@gmail.com \\ ${ }^{2}$ Progdi Teknik Komputer - Sekolah Tinggi Elektronika dan Komputer (STEKOM), \\ Mayautami@gmail.com
}

J1. Majapahit 605, Semarang, telp/fax : (024) 6723456

\section{ARTICLE INFO}

Article history:

Received 19 November 2018

Received in revised form 23 Nov 2018

Accepted 25 Nov 2018

Available online 13 Desember 2018

\begin{abstract}
The development of information systems is increasingly rapidly nowadays requires a lot of educational institutions to develop information systems in educational environments that do not fall behind with other educational institutions. It's possible the parents and students will move to the educational institutions that have information systems that fast, accurate and reliable way to get the information required with skills no doubt in supporting the learning system. SMK Negeri 4 Kendal is located at Jl. Soekarno-Hatta Kendal, very aware of the importance of information systems. The information that fast, accurate and available at all times would be very helpful in the implementation of the learning process is also in the process of admission of new students. A newly established education institution four years ago was very concerned about the availability of information systems needed by students and parents so that information systems and the fabric of cooperation to do with ease. The purpose of this research is to increase the number of new admissions and quality of service in the admission of new students and in conducting the data collection and reporting so that information needed by prospective students as well as guardians and leaders mmurid can be obtained at any time. In this research, the application used is PHP programming MySQL database.
\end{abstract}

Key word : system information, receive new student, education, registration

\section{Pendahuluan}

Seiring dengan kemajuan jaman perkembangan ilmu pengetahuan dan teknologi yang tumbuh demikian pesat di segala bidang, dewasa ini telah banyak menimbulkan perubahan sangat cepat, khususnya di bidang teknologi informasi komputer. Kecepatan, ketepatan dan keakuratan sebuah informasi sangat mutlak di butuhkan bagi usaha yang bergerak di bidang bisnis. Dalam dunia bisnis sekarang ini yang semakin kompetitif, di mana perubahan berjalan dinamis seiring dan tidak dapat di prediksi, terutama dalam hal perkembangan pengetahuan situasi ekonomi dan pangsa pasar produksi secara umum.

Received Nov 19, 2018; Revised Nov 23, 2018; Accepted Nov 25, 2018 
Saat ini kebutuhan akan informasi data semakin berkembang seiring semakin mudahnya seseorang menerima serta merespon suatu informasi. Proses tersebut menimbulkan suatu kebutuhan untuk mengakses data, salah satunya adalah melelui internet. Internet merupakan media untuk membawa informasi sedang daya guna yang bisa dimanfaatkan adalah informasi yang ada didalamnya. Internet memungkinkan pemakai di seluruh dunia untuk memakai sumber informasi tersebut secara bersama-sama. Dengan terus berkembangnya teknologi komputer saat ini menjadikan internet dapat digunakan dengan mudah untuk berbagai keperluan seperti sebagai sarana hiburan, sumber informasi alat bisnis, dan aplikasi-aplikasi lain yang tersedia selama 24 jam.

Dengan adanya fasilitas internet, website merupakan salah satu pilihan sebagai media penyampaian informasi yang dapat digunakan, melihat kemudahan dalam proses pengaksesan saat ini, website semakin banyak digunakan untuk penyediaan informasi bagi masyarakat, begitu juga lembagalembaga pendidikan, pada saat ini website merupakan salah satu faktor pendukung dalam kesuksesan dalam sebuah lembaga maupun institusi pendidikan.

SMK Negeri 4 Kendal adalah Sekolah Menengah Kejuruan yang merupakan salah satu lembaga pendidikan yang bertujuan mempersiapkan tenaga kerja tingkat menengah, serta berpotensi untuk mencetak sumber daya manusia yang berkualitas, sejak berdiri pada tahun 2005 SMK N 4 Kendal telah mempunyai empat program keahlian yaitu Rekayasa Perangkat Lunak, Teknik Otomotif, Budidaya Perikanan, Teknik Komputer dan Jaringan. Pada tahun ajaran 2009/2010 telah di buka program keahlian baru yaitu Nautika Perikanan Laut, Multi Media, dan Teknik Sepeda Motor. Dalam promosi SMK N 4 Kendal telah menggunakan website tetapi dalam penerimaan siswa baru masih bersifat konfensional atau manual, yaitu calon siswa yang akan mendaftar harus datang langsung ke SMK Negeri 4 Kendal pada waktu yang telah di tentukan oleh pihak sekolah, sehingga bagi calon siswa baru yang bertempat tinggal jauh dengan lokasi sekolah merupakan suatu kendala tersendiri. Selain itu setelah sampai di sekelah calon siswa harus melalui antrian yang panjang terlebih dahulu untuk mendaftar sehingga membutuhkan waktu yang lama karena pendaftar yang datang untuk mendaftar tidak hanya berasal dari lingkup kabupaten Kendal tapi juga dari luar kabupaten Kendal.

Di samping kendala jarak, calon siswa juga tidak dapat mengetahui jurnal harian karena dari pihak sekolah tidak membuat jurnal untuk calon siswa baru.

Tabel 1 Jumlah pendaftaran siswa baru tiga tahun terakhir

\begin{tabular}{|c|c|c|c|c|c|}
\hline Tahun & $\begin{array}{c}\text { Jumlah } \\
\text { Pendaftar }\end{array}$ & Luar Kota & dalam Kota & di Terima & $\begin{array}{c}\text { tidak di } \\
\text { Terima }\end{array}$ \\
\hline 2008 & 980 & 400 & 580 & 386 & 594 \\
\hline 2009 & 976 & 380 & 596 & 386 & 590 \\
\hline 2010 & 996 & 410 & 586 & 386 & 610 \\
\hline
\end{tabular}

Sumber:SMK N 4 kendal

Berdasarkan surat edaran PERATURAN KEPALA DINAS PENDIDIKAN, PEMUDA dan OLAHRAGA KABUPATEN KENDAL menyatakan bahwa "penerimaan peserta didik baru dengan cara yang lebih baik dapat meningkatkan mutu pendidikan dan mencapai sumber daya manusia yang berkualitas sesuai dengan kompetensi yang ditetapkan secara nasional" (Teguh,2010)

Untuk mengatasi masalah yang ada, kiranya di perlukan sebuah sistem dengan korelasi data guna menunjang pengolahan data pendaftaran siswa baru dan mengatasi masalah-masalah yang ada.

Berdasarkan uraian di atas, maka penulis bremaksud ingin merancang sebuah sistem dengan korelasi data dengan menggunakan bahasa pemograman PHP yang diharapkan dapat membantu menyelesaikan masalah atau kendala yang ada di SMK Negeri 4 Kendal khusunya di bagian penerimaan siswa baru. Dalam penulisan skripsi ini penulis mengambil judul "SISTEM PENDAFTARAN ONLINE SISWA BARU di SMK Negeri 4 KENDAL".

Dengan adanya sistem pendaftaran online calon siswa tidak harus datang langsung ke SMK N 4 Kendal untuk melakukan pendaftaran tetapi juga dapat melakukannya melalui media internet, dengan prosedur pendaftaran calon siswa membuka web pendaftaran siswa baru SMK N 4 Kendal, setelah masuk calon siswa mengisi form data siswa yang berisikan tentang data siswa, nilai UAS, dan keterangan wali. Setelah selesai melakukan input data siswa, calon siswa mencetak bukti pendaftaran yang kemudian bukti pendaftaran di bawa saat melakukan verifikasi pendaftaran di sekolah sebagai tanda bukti bahwa telah melakukan pendaftaran melalui sistem pendaftran online, dan juga membawa

PENDAFTARAN SISWA BARU ONLINE DI SMK NEGERI 4 KENDAL (Haris Ihsanil Huda) 
berkas-berkas yang di butuhkan seperti Surat Tanda Tamat Belajar, Surat Keterangan Lulus, dan lainnya yang menjadi persyaratan bagi calon siswa baru untuk melakukan pendaftaran.

\section{Landasan Teori}

1. Pengertian Perancangan

Perancangan merupakan tahap penerjemahan dari keperluan atau data yang telah dianalisis ke dalam bentuk yang mudah dimengerti oleh pemakai. Ada tiga atribut yang penting dalam proses perancangan, yaitu : struktur data, arsitektur perangkat lunak, dan prosedur rinci.

2. Pengertian Pendidikan

Pendidikan adalah usaha sadar dan terencana untuk mewujudkan suasana belajar dan proses pembelajaran agar peserta didik secara aktif mengembangkan potensi dirinya untuk memiliki kekuatan spiritual keagamaan, pengendalian diri, kepribadian, kecerdasan, akhlak mulia, serta ketrampilan yang diperlukan dirinya, masyarakat, bangsa dan negara (UU RI nomor 20,2003).

3. Pengertian Penerimaan Siswa Baru (PSB)

Penerimaan Siswa Baru (PSB) adalah proses seleksi administrasi dan akademis calon siswa untuk memasuki jenjang pendidikan setingkat lebih tinggi (UU RI nomor 20,2003).

4. Pengertian Ujian Nasional

Ujian Nasional adalah kegiatan penilaian hasil belajar siswa yang telah menyelesaikan jenjang pendidikan dan diselenggarakan secara nasional (UU RI nomor 20,2003).

5. Pengertian Nilai Ujian Nasional

Nilai Ujian Nasional adalah nilai yang diperoleh dari hasil ujian nasional yang selanjutnya disingkat NUN (UU RI nomor 20,2003).

6. Pengertian Ijazah

Ijazah adalah surat pernyataan resmi dan sah yang menyatakan bahwa seseorang peserta didik telah menyelesaikan suatu jenjang pendidikan dan diberikan setelah dinyatakan lulus Ujian Nasional dan Ujian Sekolah (UU RI nomor 20,2003).

7. Pengertian Siswa

Siswa adalah peserta didik pada SMP, SMA dan SMK (UU RI nomor 20,2003).

8. Pengertian Seleksi

Seleksi adalah penyaringan calon siswa berdasarkan persyaratan yang telah ditetapkan (UU RI nomor 20,2003).

\section{Metodologi}

Metode pengumpulan data merupakan salah satu faktor penting dalam suatu proses penyusunan skripsi dan juga merupakan suatu cara dalam mengembangkan serta menguji kebenaran dari suatu ilmu pengetahuan.

Metode yang digunakan dalam penulisan penelitian ini antara lain:

1. Objek Penelitian

Penulis memfokuskan penelitian tentang perpustakaan pada Perpustakaan SMK Negeri 4 Kendal, dengan meneliti sistem yang ada untuk kemudian mencoba merancang untuk mengembangkan menjadi sistem baru yang dianggap sesuai dengan keadaan SMK Negeri 4 Kendal

2. Jenis dan Sumber Data

Metode pengumpulan data yang digunakan dalam penyusunan meliputi dua jenis data yaitu :

a. Data Primer

Data primer adalah data-data yang diperoleh secara langsung dari tangan pertama atau sumber data itu sendiri di SMK Negeri 4 Kendal. Pelaksanaan pengumpulan data primer ini dilaksanakan dengan cara sebagai berikut :

(1) Wawancara

Wawancara adalah mengadakan tanya jawab secara langsung kepada koresponden atau sumber data yang dalam hal ini diwakili oleh bagian SMK Negeri 4 Kendal yaitu mengenai hal-hal yang menjadi obyek penelitian dari laporan ini, sehingga segala sesuatunya dapat diketahui dengan jelas.

(2) Observasi

Observasi adalah mengadakan pengamatan secara langsung pada SMK Negeri 4 Kendal yang bersangkutan, terutama sekali dengan hal-hal yang erat kaitannya

ELKOM Vol. 11, No. 2, Desember 2018: 56-66 
dengan masalah perpustakaan yang akan dibuat sehingga akan diperoleh gambaran yang jelas.

(3) Penelusuran Literatur

Cara pengumpulan data dengan menggunakan sebagian atau seluruh data yang telah ada atau laporan data dari peneliti sebelumnya.

(4) Questionair

Cara pengumpulan data dengan menggunakan daftar pertanyaan terhadap objek yang diteliti.

(5) Studi Kepustakaan

Metode pengumpulan data dengan cara melakukan pencarian data pendukung dari media elektronik, buku dan internet.

\section{b. Data Sekunder}

Data Sekunder adalah data-data yang diperoleh dalam bentuk sudah jadi, berupa publikasi atau data diperoleh dari obyek penelitian, tetapi masih mempunyai hubungan erat dengan masalah yang dibahas. Data sekunder dapat diperoleh dari perpustakaan, brosur, catatancatatan lain yang kiranya mempunyai hubungan dengan masalah yang dibahas.

3. Metode Pengumpulan Data

Metode pengumpulan data yang digunakan dalam penyusunan meliputi dua metode yaitu :

a. Metode pengumpulan data kualitatif

Yaitu dengan menjelaskan permasalahan atau data-data yang diperoleh dan dikumpulkan dari hasil riset tanya jawab dengan pengelola SMK Negeri 4 Kendal Demak yang tidak dapat diukur dengan angka. Contoh : DFD, Kamus Data, ERD, Normalisasi, dan Flowchart.

b. Metode pengumpulan data kuantitatif

Yaitu analisa data yang diperoleh dengan menggunakan angka-angka dari hasil observasi atau pengukuran.

4. Metode Analisis Data

Siklus hidup sistem merupakan suatu metodologi dalam penerapan pendekatan sistem untuk tugas mengembangkan dan menggunakan sistem berbasis komputer.

Dari rumusan masalah diatas penulis menentukan metode pengembangan sistem menggunakan SDLC (system development life cycle) atau sistem siklus hidup yang dapat digambarkan sebagai berikut :

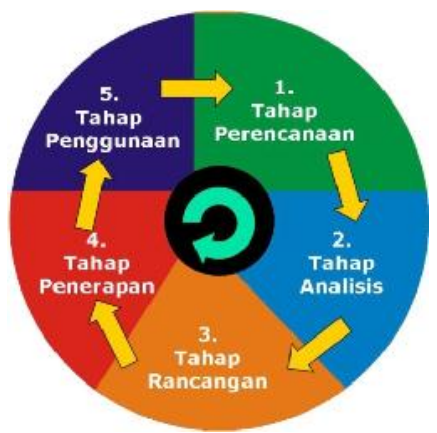

Gambar 1 Sistem Siklus Hidup

Adapun tahapan dalam sistem ini meliputi :

a. Tahap Perencanaan, yaitu tahap awal yang harus ditentukan dengan melakukan langkah langkah untuk menemukan suatu masalah, mendefinisikan masalah, menentukan tujuan, mengidentifikasikan kendala, membuat perencanaan operasional dan jadwal, serta mempersiapkan usulan penelitian sistem.

b. Tahap Analisis, yaitu penelitian atas sistem yang telah ada dengan tujuan untuk merancang sistem baru atau diperbaharui.

c. Tahap Rancangan, yaitu penentuan proses dan data yang diperlukan oleh sistem baru dan juga jenis peralatan yang akan digunakan. Dengan menyiapkan rancangan sistem yang terinci berupa rancangan terstruktur (diagram arus data) terdiri atas DFD, ERD, Database, 
Normalisasi dan rancangan tampilan input/output. Sehingga dapat mengidentifikasi serta mengevaluasi alternatif konfigurasi sistem untuk menghasilkan konfigurasi terbaik.

d. Tahap Penerapan, yaitu merupakan kegiatan memperoleh dan mengintegrasikan sumber daya fisik dan konseptual yang menghasilkan suatu sistem yang bekerja.

e. Tahap Penggunaan, yaitu merupakan kegiatan penggunaan sistem yang telah dibuat, mengevaluasi, memlihara serta menyiapkan usulan rekayasa ulang.

\subsection{Bahan Penelitian}

1. Identifikasi hadware

Hadware atau perangkat keras adalah komponen computer yang mempunyai computer yang mempunyai bentuk fisik.penulis akan mengusuhkan beberapa hadware dibawah ini, alasan pemilih hadware tersebut agar dapat menunjang jalannya system sehingga lebih nyaman dan lebih cermat. Berikut hardware yang diusulkan pada sistem yang dijalankan:
a. Processor
$\begin{array}{ll}: & \text { Pentium } 4 \\ : & 512 \mathrm{MB}\end{array}$
b. RAM
c. CD ROM/RW
d. Floppy Drive
$52 \mathrm{X}$
e. Hard Disk
f. Monitor
g. Mouse \& Keyboard
$3.5,1.44 \mathrm{Mb}$
$40 \mathrm{~Gb}$
15 " SVGA
h. Modem
Serial / PS2
$128 \mathrm{Kbps}$

2. Identifikasi Software

Untuk menjalankan aplikasi ini,software yang digunakan yaitu
a. PHP ( Hypertext Preprocessor).
b. Macromedia Dreamweaver MX 2004
c. MySQL Server, Apache
d. Adobe Photoshop

\subsection{Desain Penelitian}

Gambar 1 berikut merupakan arsitektur dari context diagram yang menggambarkan perancangan sistem baru. Entitas yang terkait meliputi Calon siswa, Panitia dan Kepala sekolah.

\begin{tabular}{|ll|}
\hline Project Name: & sisfo_psb \\
Project Path: & f:|psb_webl \\
Chart File: & sisfo_ps.dfd \\
Chart Name: & Yourdon-Context Diagram \\
Created On: & Jan-06-2011 \\
Created By: & haris \\
Modified On: & Mar-26-2011 \\
Modified By: & haris \\
\hline
\end{tabular}

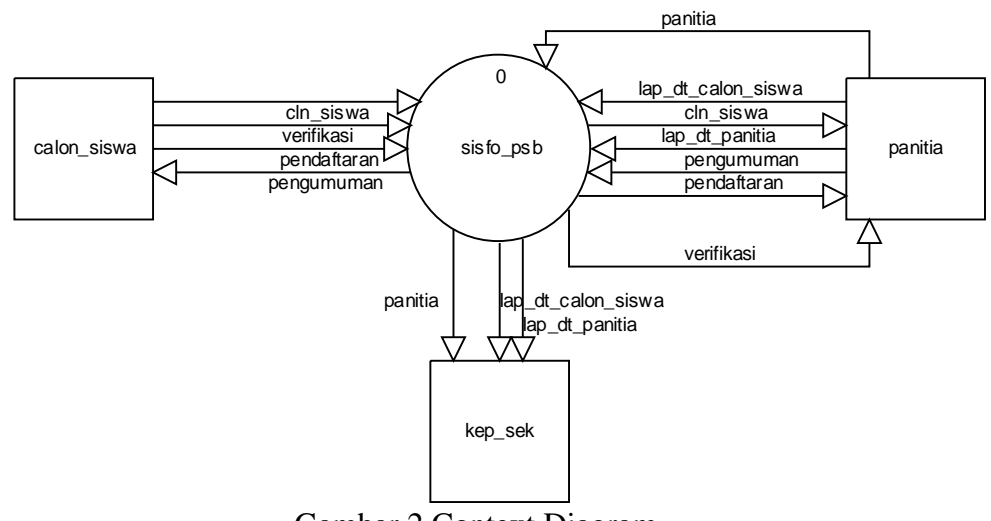

Gambar 2 Context Diagram

ELKOM Vol. 11, No. 2, Desember 2018: $56-66$ 
61

\subsection{Perancangan}

a. Halaman desain utama

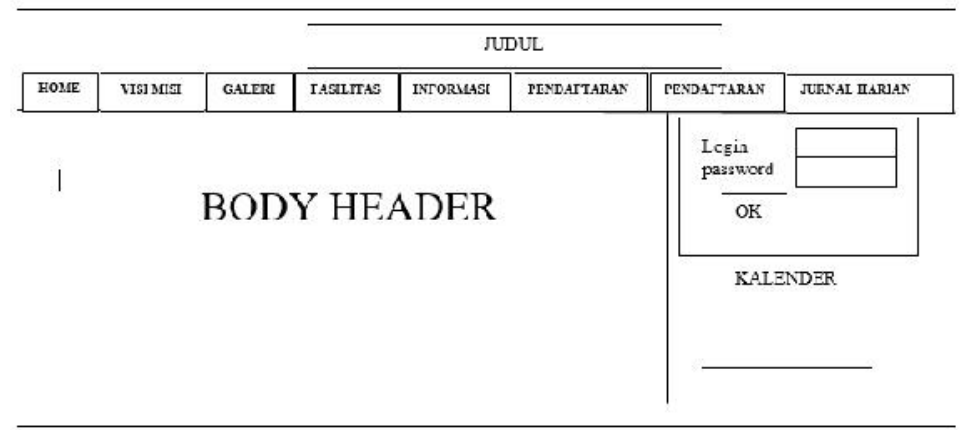

Gambar 3 Desain Halaman Utama

b. Halaman pendaftaran

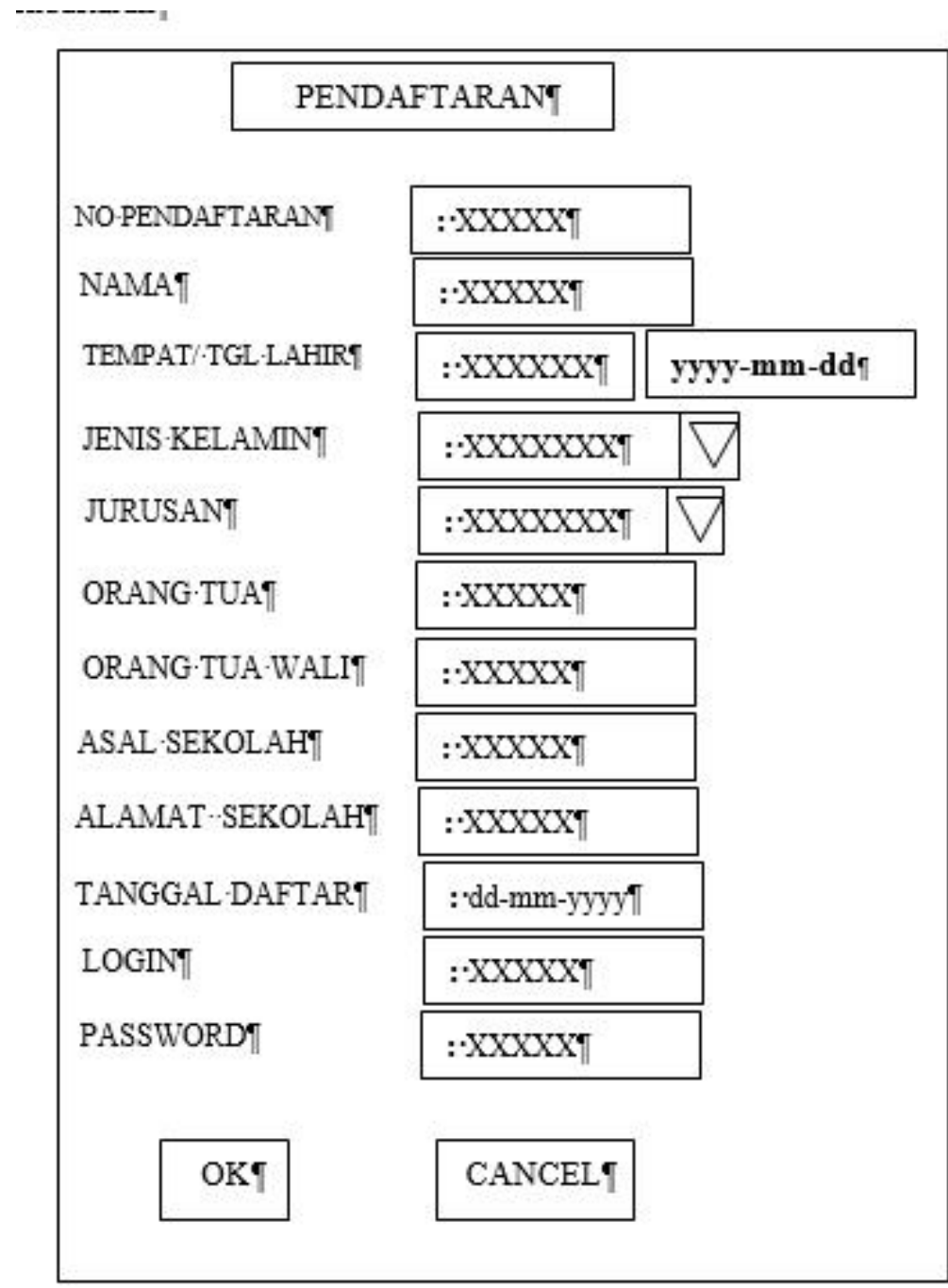

Gambar 4 Desain Halaman Pendaftaran 
c. Halaman Jurnal Harian

\begin{tabular}{|c|c|c|c|}
\hline $\begin{array}{c}\text { NO } \\
\text { PENDAFTARAN }\end{array}$ & NAMA & JENIS KELAMIN & JURUSAN \\
\hline 99 & XXXXXXXX & XXXXXX & XXXXX \\
\hline
\end{tabular}

Gambar 5 Desain Halaman Jurnal Harian

\section{Hasil dan Pembahasan}

a. Halaman utama

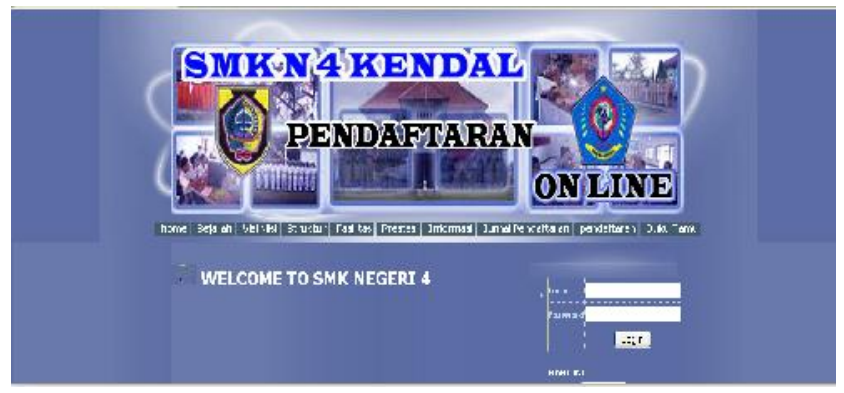

Gambar 6 Tampilan Halaman Utama

b. Halaman pendaftaran

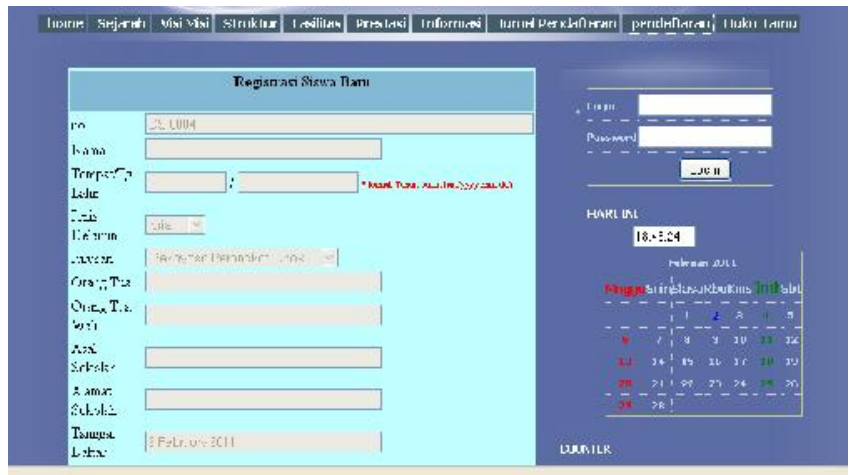

Gambar 7 Tampilan Halaman Pendaftaran Siswa Baru

c. Halaman jurnal harian

\begin{tabular}{|c|c|c|c|c|c|c|c|c|}
\hline \multicolumn{9}{|c|}{ Daftar Calon Siswa } \\
\hline \begin{tabular}{|l|} 
No \\
Pendaftar
\end{tabular} & Nama & Tcmpat/ & Tgl Lahir & \begin{tabular}{|l|} 
Jenis \\
Kelamin \\
\end{tabular} & Jurusan & $\begin{array}{l}\text { sal } \\
\text { Sekolah }\end{array}$ & Nilai & $\begin{array}{l}\text { Tanggal } \\
\text { Daftar }\end{array}$ \\
\hline DS-0001 & $\begin{array}{l}\text { nadi } \\
\text { mailana }\end{array}$ & jepara & $06-01-1987$ & wanita & $\begin{array}{l}\text { Teknik } \\
\text { Otomotif }\end{array}$ & sma In & 75 & \begin{tabular}{|l}
25 \\
January \\
2011
\end{tabular} \\
\hline DS-0002 & haris & kendal & $20-04-1988$ & pria & \begin{tabular}{|l|} 
Rekayasa \\
Perangkat \\
Lunak
\end{tabular} & sma i & 85 & \begin{tabular}{|l}
25 \\
January \\
2011
\end{tabular} \\
\hline DS -0003 & agus & jepara & $12-10-1988$ & pria & $\begin{array}{l}\text { Multi } \\
\text { Media }\end{array}$ & $\begin{array}{l}\operatorname{smp} 1 \\
\text { kelet }\end{array}$ & 80 & \begin{tabular}{|l}
27 \\
January \\
2011
\end{tabular} \\
\hline DS0004 & rizki & semarang & $20-03-1990$ & pria & $\begin{array}{l}\text { Rekayasa } \\
\text { Perangkat } \\
\text { T.unak }\end{array}$ & smp 1 & 80 & $\begin{array}{l}1 \text { April } \\
2011\end{array}$ \\
\hline DS0005 & rizki & kcndal & $30-01-1992$ & pria & $\begin{array}{l}\text { Budidaya } \\
\text { Perikariant }\end{array}$ & $\begin{array}{l}\text { smp } 1 \\
\text { kentidal }\end{array}$ & 85 & $\begin{array}{l}1 \text { April } \\
2011\end{array}$ \\
\hline 150006 & sulung & pemalang & $12-12-1993$ & pria & $\begin{array}{l}\text { Telcnik } \\
\text { Sepeda } \\
\text { Motor }\end{array}$ & $\begin{array}{l}\operatorname{smp} 3 \\
\text { Kendal }\end{array}$ & 85 & $\begin{array}{l}1 \text { April } \\
2011\end{array}$ \\
\hline
\end{tabular}

Gambar 8 Tampilan Jurnal Harian

ELKOM Vol. 11, No. 2, Desember 2018: 56-66 
d. Halaman Edit Data

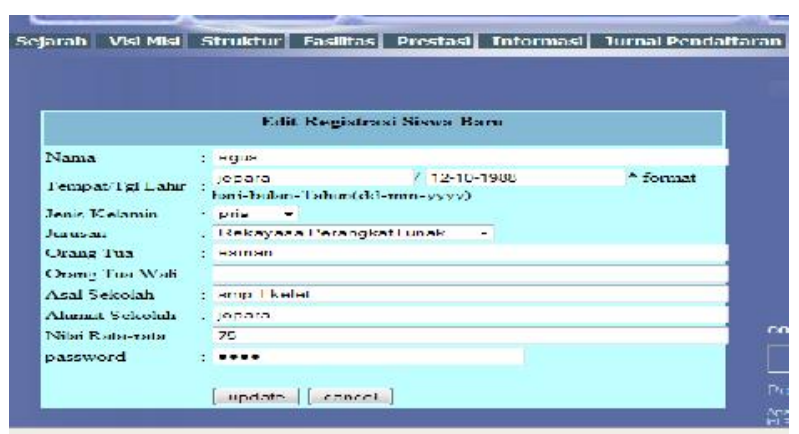

Gambar 9 Tampilan Edit Data

e. Halaman Bukti Pendaftaran

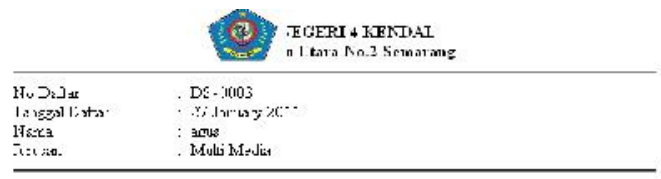

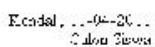

Gambar 10Tampilan Bukti Pendaftaran

f. Halaman Pengumuman

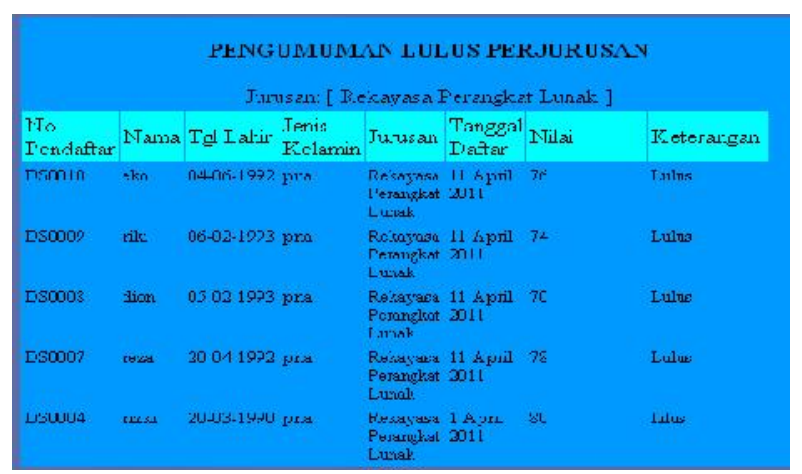

Gambar 11 Tampilan Halaman Pengumuman

g. Halaman Admin

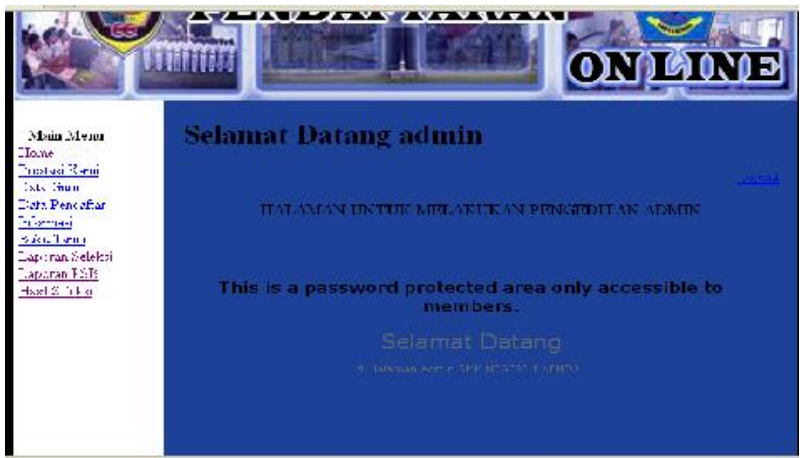

Gambar 12 Tampilan Halaman awal Admin 
h. Halaman Data Pendaftar

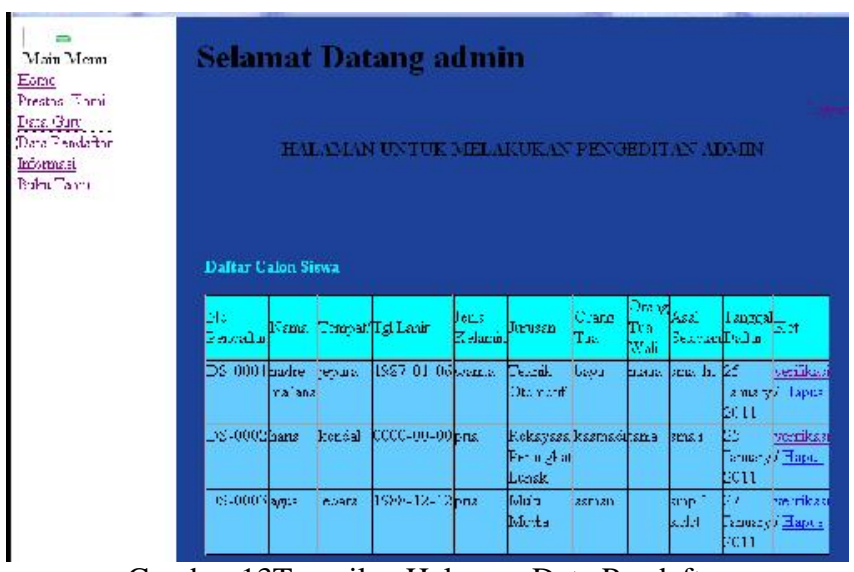

Gambar 13Tampilan Halaman Data Pendaftar

i. Halaman Verifikasi

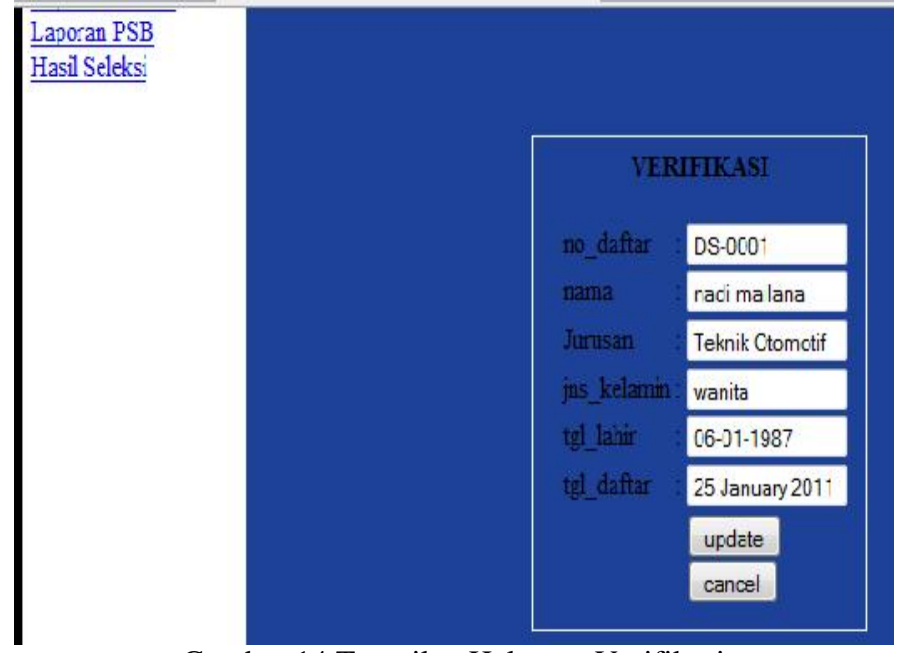

Gambar 14 Tampilan Halaman Verifikasi

j. Laporan Hasil Seleksi

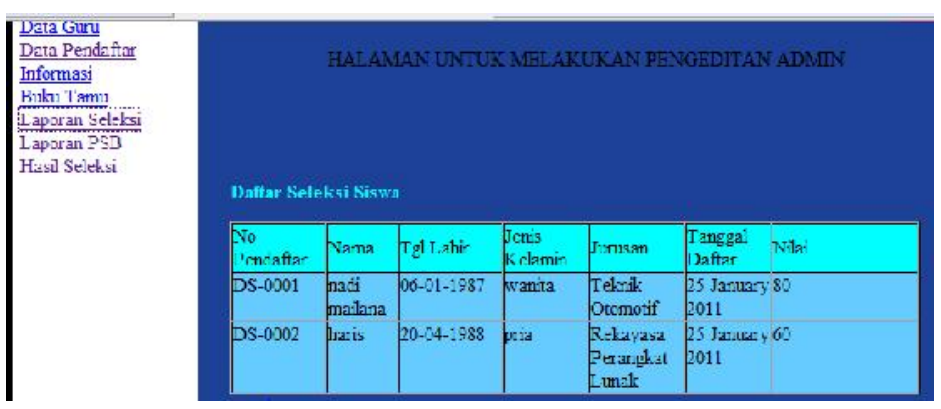

Gambar 15 Tampilan Halaman Laporan Hasil Seleksi

ELKOM Vol. 11, No. 2, Desember 2018 : 56-66 
k. Halaman Laporan Penerimaan Siswa Baru

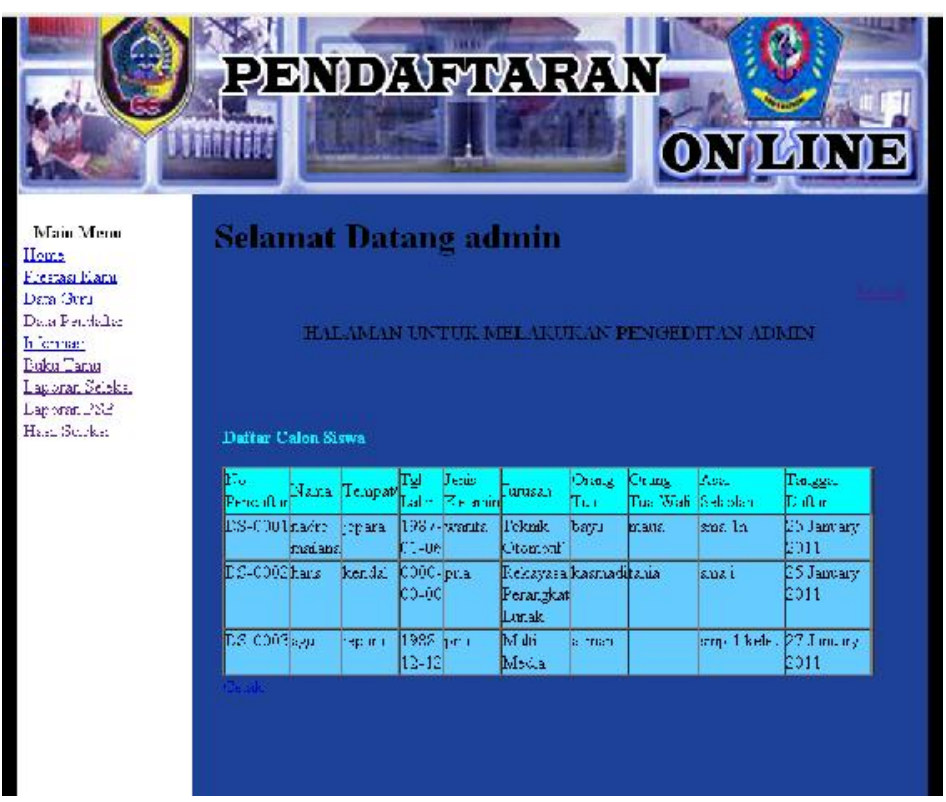

Gambar 16 Tampilan Halaman Laporan Penerimaan Siswa Baru

1. Halaman Hasil Seleksi

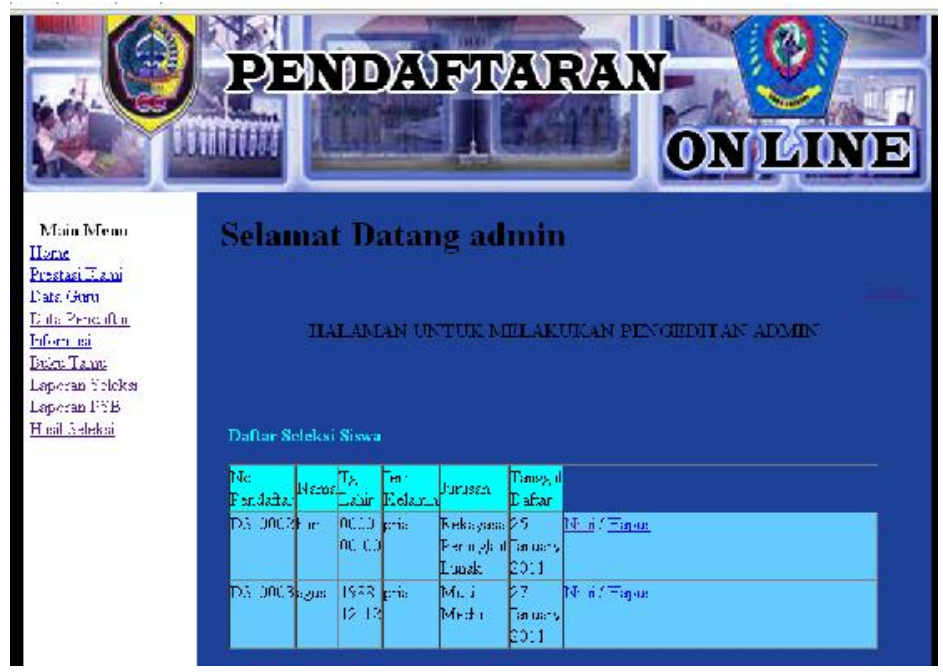

Gambar 17 Tampilan Halaman Hasil Seleksi

\section{Kesimpulan}

Dari hasil penelitian dan analisa sistem lama, kemudian dikembangkan ke dalam sistem baru yang dituangkan dalam penyusunan skripsi ini, maka dapat ditarik kesimpulan sebagai berikut :

1. Sistem yang dilakukan dalam penerimaan siswa baru di SMK Negeri 4 Kendal masih menggunakan sistem konvensional.

2. Kelemahan pada sistem penerimaan siswa baru secara konvensinal yaitu seperti terjadinya antrian pada saat penerimaan siswa baru. 
3. Bagi calon siswa yang tinggal jauh dari lokasi sekolah merupakan kendala tersendiri, selain itu calon siswa yang ingin mendapatkan informasi jurnal penerimaan siswa baru harus datang langsung ke sekolah.

4. Dengan adanya sistem penerimaan siswa baru online diharapkan dapat memecahkan masalah yang terjadi pada saat penerimaan siswa baru di SMK Negeri 4 Kendal.

\section{Daftar Pustaka}

Agus, M. 2008, Internet, Gramedia, Jakarta.

Amsyah, Zulkifli. 2001, Manajemen Sistem Informasi, PT. Gramedia Pustaka Utama, Jakarta

Davis,Gordon B. 1999, Sistem Informasi Manajemen, PT. Pustaka Pressindo, Jakarta.

Dwidjanto, Teguh.2010, Pedoman pelaksanaan penerimaan peserta didik baru di lingkungan pembinaan dinas pendidikan pemuda dan olahraga kabupaten kendal, Dinas Pendidikan Pemuda dan Olahraga Kabupaten Kendal, Kendal.

Juju, Dominikus dan Syukrie Muhammad. 2009, Jurus Jitu Pembuatan Web Free Lance, PT. Elex Media Komputindo, Jakarta.

Musyawarah, Rina. 2005, Membangun Apilikasi Database Berbasis Web Untuk Pemula, PT. Elex Media Komputindo, Jakarta.

Rafiza, H. 2006, Panduan dan Referensi Kamus Fungsi PHP 5, PT. Elex Media Komputindo, Jakarta.

Soeherman, Bonnie. \& Pinontoan, Marion. 2008, Designing Information System, PT.Elex Media Komputindo, Jakarta.

Supriansyah, Haris. \& Kartoyo. 2007, 30 menit Menjadi Web Master, OASE Mata Air Makna, Bandung.

Sutarman. 2008, Membangun Aplikasi Web dengan PHP dan MySQL, Graha Ilmu, Yogyakarta.

Undang-undang Republik Indonesia Nomor 20 tahun 2003 tentang sisdiknas, Citra Umbara, Bandung.

Wahyono, Teguh. 2005, Pemrograman Web Dinamis, PT. Elex Media Komputindo, Jakarta.

Yuhefizar. 2008, 10 Jam Menguasai Internet: Teknologi dan Aplikasinya, PT. Elex Media Komputindo, Jakarta.

Zaki, A. 2008, PHP dan MySQL, PT. Gramedia Pustaka Utama, Jakarta.

ELKOM Vol. 11, No. 2, Desember 2018: 56-66 